\title{
Grapevine Injury and Fruit Yield Response to Simulated Auxin Herbicide Drift
}

\author{
Steven C. Haring, Junjun Ou, Kassim Al-Khatib, and \\ Bradley D. Hanson \\ Department of Plant Sciences, University of California, One Shields Avenue, \\ Davis, CA 95616
}

Additional index words. auxinic herbicide, herbicide symptomology, off-target movement, vines, Vitis vinifera, winegrape

\begin{abstract}
Grape growers are concerned about the potential impact of drift from commonly used auxinic herbicides. In California, this is frequently related to herbicides used in cereals and noncrop areas, whereas in other parts of the United States concerns are often related to dicamba- and 2,4-D-resistant cropping systems. Our objective was to compare the relative sensitivity of winegrapes to simulated auxinic herbicide drift, including grapevine symptomology, grape yield, and grape quality. In a small-plot herbicide evaluation, we applied $1 / 900 \times, 1 / 300 \times, 1 / 100 \times$, and $1 / 33 \times$ rates of $2,4-\mathrm{D}$, aminopyralid, dicamba, and triclopyr based on $1 \times$ field rates of $1454,122.5,280$, and $2240 \mathrm{~g} \cdot \mathrm{ha}^{-1}$ ae, respectively. Aminopyralid resulted in similar symptomology to 2,4-D and dicambanamely, leaf cupping, leaf crinkling, excessive tendril twisting, and tendril death, although these symptoms were generally subtle. Triclopyr resulted in much greater levels of necrosis compared with the other herbicides. In our study, triclopyr was the only herbicide associated with grape yield loss, and greater triclopyr rates were also associated with increased grape sugar levels. This study demonstrates that grapes are sensitive to low rates of simulated herbicide drift, but symptoms do not necessarily indicate yield loss or quality effects. This study indicates that auxin-type herbicide simulated drift symptoms are not reliable markers for winegrape yield or quality reduction.
\end{abstract}

Auxin herbicides are known to create high-risk drift scenarios for grape growers. Simulated 2,4-D drift as low as $1 / 100 \times$ of a field use rate has caused herbicide symptoms on grapes, including season-long symptomology and symptoms in the following season's regrowth (Al-Khatib et al., 1993; Bhatti et al., 1996, 1997). Dicamba and 2,4-D have each been shown to be injurious to summer grape (Vitis aestivalis) (Dintelmann et al., 2020). Furthermore, these two herbicides have caused symptoms on greenhouse-grown grapes down to a $1 / 300 \times$ fractional rate (Mohseni-Moghadam et al., 2016); however, greenhouse-grown grapes are generally more susceptible to herbicide exposure than field-

Received for publication 18 Oct. 2021. Accepted for publication 9 Dec. 2021.

Published online 28 January 2022.

We gratefully acknowledge the efforts of Caio Brunharo, Alex Ceseski, Matthew Fatino, Nate Kane, Guy Kyser, Katie Martin, Sarah Morran, Gale Perez, John Roncoroni, Seth Watkins, and Drew Wolter for their fieldwork assistance on this project. This research was performed on lands that are the traditional home of Patwin people, and the Patwin people remain committed to the stewardship of these lands as they have been over many centuries.

Current address for J.O.: Corteva Agriscience, Indianapolis, IN

S.C.H. is the corresponding author. E-mail: sharing@ucdavis.edu.

This is an open access article distributed under the CC BY-NC-ND license (https://creativecommons. org/licenses/by-nc-nd/4.0/). grown grapes (Al-Khatib et al., 1992). In well-studied systems such as soybeans, researchers have difficulty finding a noninjurious, nonzero dose of dicamba, nor have they found a reliable way to use symptoms caused by off-target herbicide movement as an early indicator for yield reduction (AlKhatib and Peterson, 1999; Kniss, 2018).

Although typical auxin herbicide symptoms are recognized easily by many grape growers, there is a relative lack of understanding of more in-depth growth and yield impacts of different auxin herbicides. Previous research has focused primarily on symptoms caused by the auxin herbicides 2,4-D and dicamba, to fractional field use rates as low as $1 / 300 \times$ (Al-Khatib et al., 1993; Bhatti et al., 1997; Mohseni-Moghadam et al., 2016). Therefore, it is important to compare the symptoms from these known herbicides and drift rates to different auxin herbicides and lower rates. A need exists to link herbicide symptoms to grape yield and yield quality, search for a noninjurious herbicide dose, and understand how auxin herbicides other than 2,4-D and dicamba may produce different results. This information could support management decisions in response to suspected herbicide drift, including identification of the drifting herbicide and delineating between injurious and less-damaging herbicide symptoms.

When exposed to auxin herbicides, grapes often display symptoms including epinasty, altered leaf shape, abnormal shoot morphology, and altered cellular architecture (Bondada, 2011). However, more specificity is needed to improve our understanding of these symptoms, particularly in terms of the subtle symptomology differences that distinguish various auxin herbicides and rates. Because grapes are widespread, valuable, perennial, and culturally important, off-target herbicide movement can be critical for grape growers. Severe injury or plant death from off-target herbicide movement could result in the destruction of years of investment in a vineyard, but sublethal doses can also be extremely problematic because of the demand for high-quality or premium grapes.

Grape is the most valuable horticultural crop in California, with more than 350,000 ha of wine, table, or raisin grapes planted throughout the state's major crop production regions (California Department of Food and Agriculture, 2020). Grapes are grown alongside more than 400 different commodities in California, representing more than US\$50 billion in cash receipts (California Department of Food and Agriculture, 2020). In many areas of the United States and in recent years, herbicide drift research has focused on 2,4-D and dicamba because of widespread use in trait-linked soybean and cotton varieties. However, these systems are not used in California, and the local grape industry is most concerned about auxinic herbicides used in the region, particularly in rangelands and rights-of-way. These noncrop areas are likely to be managed with auxin herbicides other than dicamba and 2,4-D, and the timing of weed management in these areas may coincide with important portions of grape development in the early summer (DiTomaso, 2000). Off-target pesticide movement is one of many challenges associated with California's highly diverse landscape. The logistical challenges of pesticide application multiply when considering the numerous pesticide materials, application methods, and phenologies at play in California cropping systems.

We evaluated 'Grenache' winegrape responses, including herbicide symptomology, fruit yield, and sugar content, to simulated, low-rate auxin herbicide drift, including 2,4-D, aminopyralid, dicamba, and triclopyr. We expected to find that simulated drift of each of the four auxin herbicides can cause a variety of effects, from grape yield loss at higher drift rates to no visible symptoms, quality penalty, or yield loss at very low drift rates.

\section{Materials and Methods}

A field research study was initiated in June 2018 in a mature, double-cordon-trained 'Grenache' vineyard at the University of California Davis Department of Viticulture and Enology Tyree Vineyard in Davis, CA (lat. $38^{\circ} 31^{\prime} 31^{\prime \prime} \mathrm{N}$, long. $\left.121^{\circ} 47^{\prime} 19^{\prime \prime} \mathrm{W}\right)$. The vineyard was established in 1998. Plots included two treated vines, with an untreated buffer vine in the same row between each plot. The experiment was arranged in a randomized complete block design with three replicates, each in a separate vine row. The experiment was repeated for a second year, and the same 
2,4-D
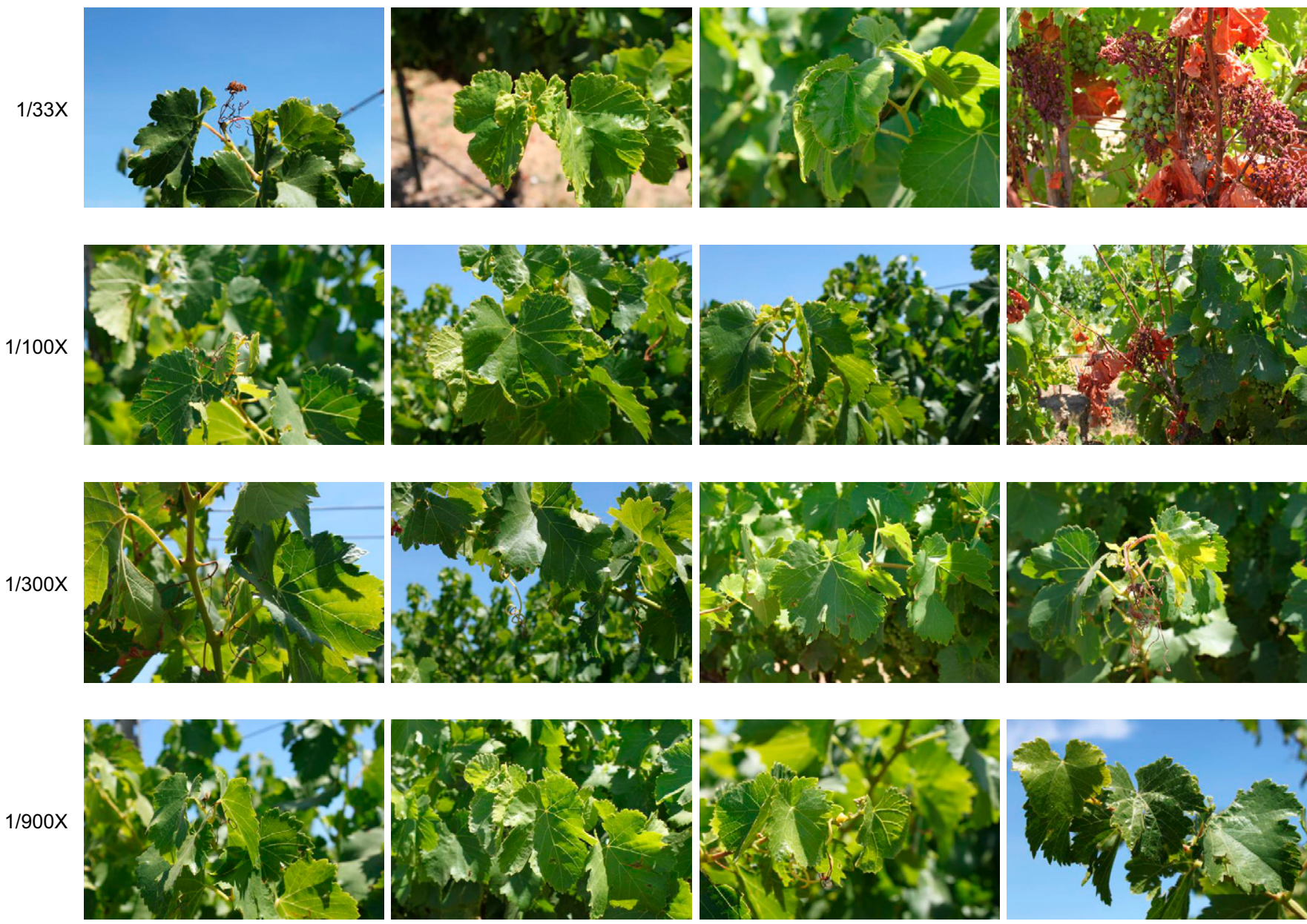

Fig. 1. Representative photos of leaf and tendril symptoms caused by four herbicides at each of four simulated drift dates. Photos were taken on 9 July 2019,4 weeks after herbicides were applied in the second year of the study. Triclopyr at $1 / 33 \times$ and $1 / 100 \times$ fractional rates resulted in severe leaf, tendril, and fruit necrosis, whereas each of the other herbicide-rate combinations resulted in relatively minor leaf cupping and/or crinkling and some tendril necrosis.

plots and layout were used when treatments were reapplied in June 2019.

Herbicide treatments were applied to one side of the vine canopy with a two-nozzle, carbon dioxide-propelled backpack sprayer calibrated to spray $187 \mathrm{~L} \cdot \mathrm{ha}^{-1}$ through TeeJet AIXR11002 nozzles (TeeJet Technologies, Wheaton, IL). The sprayer had 50-cm nozzle spacing, was operated at $4 \mathrm{kph}$ ground speed, and was oriented parallel to the leaf canopy $\approx 50 \mathrm{~cm}$ away. These calibration parameters required a $165-\mathrm{kPa}$ spray pressure in 2018 and a 193-kPa pressure in 2019. Wind speeds were less than $10 \mathrm{~m} \cdot \mathrm{s}^{-1}$ during each application. A tarp was placed over the vine row opposite the herbicide application to minimize drift between plots in the study. Treatments were applied around the time of fruit set, with berry diameter between 5 and 10 $\mathrm{mm}$, on 13 June 2018 , and again to the same plots on 11 June 2019.

Each treatment consisted of one auxin herbicide applied in a single simulated drift event each year of the study. Each herbicide was applied at four fractional rates, for a total of
Table 1. Estimates of visible herbicide symptomology on grapes from one season of visual evaluation after simulated herbicide drift on 11 June 2019.

\begin{tabular}{|c|c|c|c|c|c|}
\hline \multirow[b]{3}{*}{ Herbicide } & \multirow[b]{3}{*}{ Fractional rate } & \multicolumn{4}{|c|}{ Visible herbicide symptomology (\%) } \\
\hline & & $7 \mathrm{DAT}$ & 14 DAT & $28 \mathrm{DAT}$ & $56 \mathrm{DAT}$ \\
\hline & & \multicolumn{4}{|c|}{ Visible herbicide symptomology (\%) } \\
\hline Nontreated & - & $0.0 \mathrm{e}^{\mathrm{z}}$ & $0.0 \mathrm{f}$ & $0.0 \mathrm{~h}$ & $0.0 \mathrm{e}$ \\
\hline $2,4-\mathrm{D}$ & $1 / 900 \times$ & $5.7 \mathrm{~cd}$ & $10.0 \mathrm{c}-\mathrm{e}$ & $3.7 \mathrm{gh}$ & $4.3 \mathrm{c}-\mathrm{e}$ \\
\hline 2,4-D & $1 / 300 \times$ & $7.3 \mathrm{~cd}$ & $5.7 \mathrm{e}$ & $6.7 \mathrm{~d}-\mathrm{g}$ & $5.0 \mathrm{~cd}$ \\
\hline $2,4-\mathrm{D}$ & $1 / 100 \times$ & $6.7 \mathrm{~cd}$ & $7.3 \mathrm{de}$ & $5.0 \mathrm{fg}$ & $6.0 \mathrm{~cd}$ \\
\hline $2,4-\mathrm{D}$ & $1 / 33 \times$ & $9.7 \mathrm{c}$ & $9.7 \mathrm{c}-\mathrm{e}$ & $9.7 \mathrm{c}-\mathrm{e}$ & $6.7 \mathrm{~cd}$ \\
\hline Aminopyralid & $1 / 900 \times$ & $5.7 \mathrm{~cd}$ & $7.3 \mathrm{de}$ & $4.3 \mathrm{fg}$ & $4.3 \mathrm{c}-\mathrm{e}$ \\
\hline Aminopyralid & $1 / 300 \times$ & $6.3 \mathrm{~cd}$ & $9.7 \mathrm{c}-\mathrm{e}$ & $5.7 \mathrm{fg}$ & $4.3 \mathrm{c}-\mathrm{e}$ \\
\hline Aminopyralid & $1 / 100 \times$ & $5.0 \mathrm{~d}$ & $6.3 \mathrm{e}$ & $8.0 \mathrm{c}-\mathrm{f}$ & $6.3 \mathrm{~cd}$ \\
\hline Aminopyralid & $1 / 33 \times$ & $9.7 \mathrm{c}$ & $10.3 \mathrm{c}-\mathrm{e}$ & $10.3 \mathrm{~cd}$ & $8.0 \mathrm{~cd}$ \\
\hline Dicamba & $1 / 900 \times$ & $5.0 \mathrm{c}$ & $6.7 \mathrm{de}$ & $4.3 \mathrm{fg}$ & $4.3 \mathrm{c}-\mathrm{e}$ \\
\hline Dicamba & $1 / 300 \times$ & $6.7 \mathrm{~cd}$ & $5.3 \mathrm{e}$ & $5.7 \mathrm{fg}$ & $5.3 \mathrm{~cd}$ \\
\hline Dicamba & $1 / 100 \times$ & $9.7 \mathrm{c}$ & $9.0 \mathrm{c}-\mathrm{e}$ & $5.7 \mathrm{fg}$ & $7.3 \mathrm{~cd}$ \\
\hline Dicamba & $1 / 33 \times$ & $7.3 \mathrm{~cd}$ & $11.7 \mathrm{~cd}$ & $6.3 \mathrm{e}-\mathrm{g}$ & $7.0 \mathrm{~cd}$ \\
\hline Triclopyr & $1 / 900 \times$ & $7.3 \mathrm{~cd}$ & $9.0 \mathrm{c}-\mathrm{e}$ & $5.0 \mathrm{fg}$ & $3.7 \mathrm{de}$ \\
\hline Triclopyr & $1 / 300 \times$ & $16.7 \mathrm{~b}$ & $14.0 \mathrm{c}$ & $11.7 \mathrm{c}$ & $8.3 \mathrm{c}$ \\
\hline Triclopyr & $1 / 100 \times$ & $15.7 \mathrm{~b}$ & $25.0 \mathrm{~b}$ & $21.7 \mathrm{~b}$ & $18.3 \mathrm{~b}$ \\
\hline Triclopyr & $1 / 33 \times$ & $25.0 \mathrm{a}$ & $40.0 \mathrm{a}$ & $45.0 \mathrm{a}$ & $45.0 \mathrm{a}$ \\
\hline
\end{tabular}

${ }^{\mathrm{z}}$ Any two means within a column not followed by the same letter are significantly different at $P \leq$ 0.05 using Tukey's honestly significant difference test.

$\mathrm{DAT}=$ days after treatment. 
16 treatments, in addition to a nontreated check. The auxin herbicides and $1 \times$ field rates used in this research were based on commonly used treatments in pastures and rangelands in California. Notably, new, low-volatility formulations of 2,4-D and dicamba were not included in this study because they were not currently registered in California. The herbicides used were $2,4-\mathrm{D}$ at $455 \mathrm{~g} \cdot \mathrm{L}^{-1}$ ae $(2,4-\mathrm{D}$ Amine 4; Winfield Solutions, St. Paul, MN; $1 \times=1454$ $\mathrm{g} \cdot \mathrm{ha}^{-1}$ ae), aminopyralid at $240 \mathrm{~g} \cdot \mathrm{L}^{-1}$ ae (Milestone; Dow AgroSciences, Indianapolis, IN; $\left.1 \times=122.5 \mathrm{~g} \cdot \mathrm{ha}^{-1} \mathrm{ae}\right)$, dicamba at $480 \mathrm{~g} \cdot \mathrm{L}^{-1}$ ae (Clarity; BASF Corporation, Research Triangle Park, NC; $\left.1 \times=280 \mathrm{~g} \cdot \mathrm{ha}^{-1} \mathrm{ae}\right)$, and triclopyr at $359 \mathrm{~g} \cdot \mathrm{L}^{-1}$ ae (Garlon 3A, Dow AgroSciences, $\left.1 \times=2240 \mathrm{~g} \cdot \mathrm{L}^{-1} \mathrm{ae}\right)$. In accordance with labeled application instructions, aminopyralid was applied with $1 \% \mathrm{v}$ :v crop oil concentrate, and triclopyr was applied with $0.25 \%$ v:v nonionic surfactant, based on the volume of spray mix. The simulated drift rates were $1 / 900 \times, 1 / 300 \times, 1 / 100 \times$, and $1 / 33 \times$.

The vines were monitored for visible symptoms 7, 14, 28, and $56 \mathrm{~d}$ after treatment. Low levels of herbicide symptomology in the first year of the study resulted in discontinuation of numerical visual ratings $14 \mathrm{~d}$ after treatment, although grapevine health was scouted throughout the study period. In the second year of the study, ratings were continued until $56 \mathrm{~d}$ after reapplication of the treatments, although symptoms were again subtle in most treatments. During fruit ripening, we used a handheld refractometer to monitor grape sugar content through total soluble solids (degrees Brix) several times weekly. Data from visual evaluations were analyzed using analysis of variance and Tukey's honestly significant difference in the AOV Means Table function in ARM 2019.8 (GDM Solutions, Inc., Brookings, SD), with significance set at $P<0.05$.

Plots were hand harvested when berries in nontreated plots reached $\approx 20{ }^{\circ}$ Brix, on 29 Aug. both years. Grape clusters were harvested from both treated vines in each plot in 2018, and from a single vine in each plot in 2019. We weighed total fruit yield and used a handheld refractometer to measure sugar content from a subsample of each plot consisting of the mixed juice from $\approx 250$ to $500 \mathrm{~g}$ of representative berries.

Grape yield and sugar data were analyzed with analysis of covariance (ANCOVA) using R 3.5.3 (R Core Team, 2019). We used sequential linear models for hypothesis testing using the method described by Kniss and Streibig (2018). We used only fixed-effects regressions because of the number of siteyears in the study. This dataset met the assumption of linearity within the tested range of herbicide rates, despite the nonlinearity of similar data in previous studies that use different herbicide rate ranges. Therefore, one ANCOVA for grape yield, expressed as a percentage relative to the nontreated control treatment, used a linear model with the predictor variables herbicide and fractional use rate along with their interactions. The ANCOVA for grape sugar content, expressed as a percentage relative to the nontreated control treatment, used the same predictors.

\section{Results and Discussion}

All herbicide treatments caused some level of visible symptoms in both years of the experiment, including leaf cupping or crinkling and inconsistent veraison (onset of ripening). Triclopyr at all rates in our study also caused severe leaf, cane, and fruit necrosis. In contrast, symptoms of 2,4-D, aminopyralid, and dicamba were similar. However, low rates of 2,4-D were associated primarily with tendril necrosis. Notably, dicamba caused excessive tendril twisting in many areas without causing tendril necrosis. Dicamba was also more likely to cause leaf cupping, whereas leaf crinkling and wrinkling without cupping were characteristic symptoms of aminopyralid exposure (Fig. 1).

Symptoms were evident at the first rating date, $7 \mathrm{~d}$ after treatment, and generally peaked $14 \mathrm{~d}$ after treatment. Symptoms related to leaf malformation became relatively less prominent by 28 and $56 \mathrm{~d}$ after treatment. In contrast, necrotic symptoms appeared quickly and persisted throughout the observation period. Based on visual symptom ratings in 2019, only the $1 / 33 \times$ and $1 / 100 \times$ rates of triclopyr resulted in statistically greater symptoms throughout the evaluation period (Table 1). Other herbicide treatments caused similar symptom levels to one another, at less than $10 \%$ or statistically similar, and symptoms were typically limited to leaf and tendril malformations. In contrast, triclopyr was easily distinguishable from other herbicides because

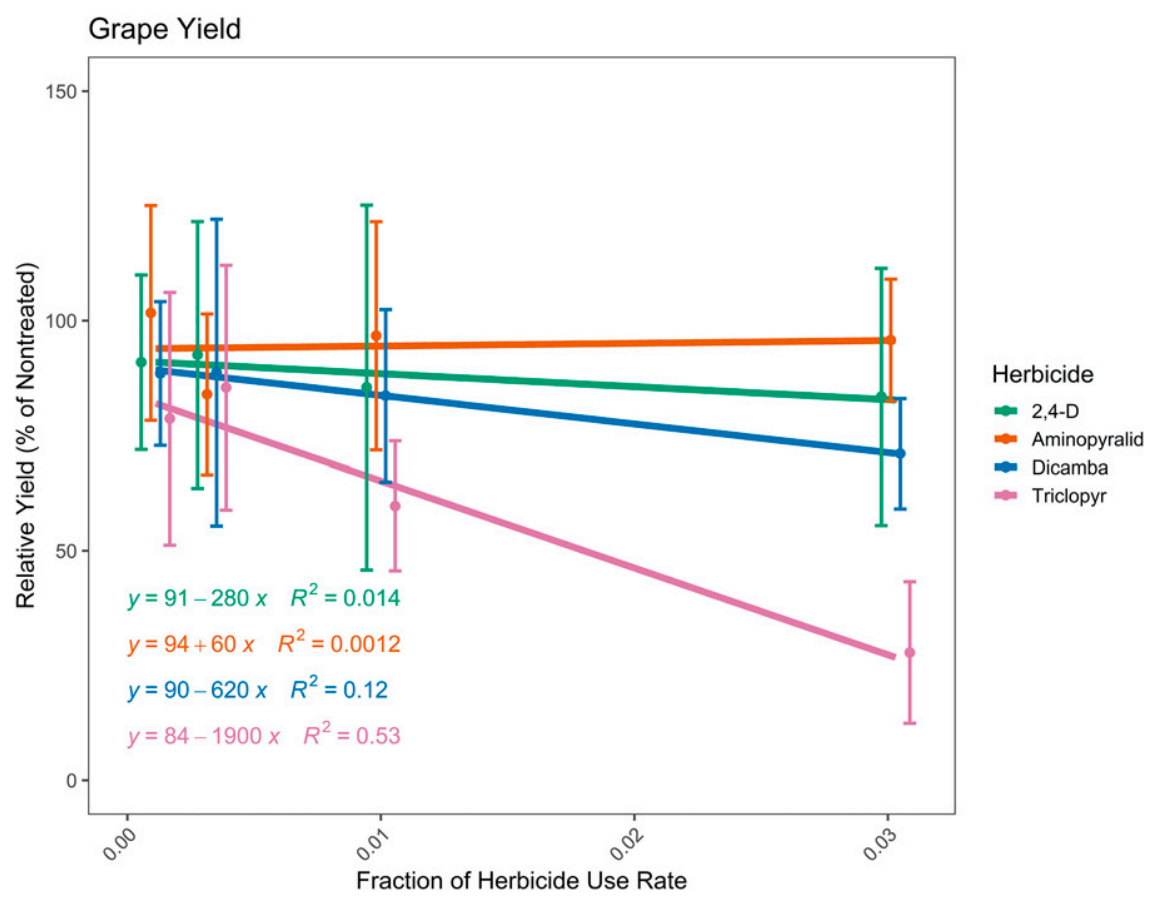

Fig. 2. Grape yield across four herbicides applied with four simulated drift rates. Data are pooled across the 2018 and 2019 grape harvests. Linear regression lines depict the relationship between fractional herbicide rate and crop yield relative to the nontreated check, separated by herbicide. Error bars represent SE. Points and error bars at each fractional use rate are slightly offset along the horizontal axis for presentation purposes. of general necrotic symptoms rather than the more subtle forms of epinasty.

Symptoms in this study were observed primarily on the side of the vine on which the spray solution was applied, possibly as a result of limited translocation of very low-concensubtlety of most symptoms reinforces the need for more options for assessing suspected off-target movement. General similarities in visible symptomology across drift rates and throughout the growing season for 2,4-D, aminopyralid, and dicamba likely necessitate the use of additional diagnostic tools such as chemical analysis for herbicide identification after a suspected drift event. Further development of alternative diagnostic tools, such as hyperspectral imaging, could be useful as well (Suarez et al., 2017).

Compared with previous research, our study found lower levels of symptoms caused by $2,4-\mathrm{D}$ and dicamba, although this finding is consistent with results demonstrating that young plants, such as greenhouse plants or recent transplants from nursery stock, are more susceptible to herbicide injury compared with the more mature, field-grown plants used in our study (Al-Khatib et al., 1992, 1993; Dintelmann et al., 2020; Mohseni-Moghadam et al., 2016). Furthermore, the timing of simulated herbicide drift in our study, which coincided with typical summer herbicide applications in irrigated pastures, likely caused some differences compared with previous studies, which used spring timings. Our study continues to support findings that symptoms can occur from very low rates tration spray solutions used in our study. The of these herbicides. We also demonstrate that 
triclopyr is much more injurious, and aminopyralid is similarly injurious to grape, in comparison with 2,4-D and dicamba.

Grape yield did not vary with herbicide rate for 2,4-D, aminopyralid, and dicamba, and there were no differences in grape yield among these herbicides. The relationship between triclopyr rate and relative grape yield was significant $(P=0.006)$, and a lower yield was associated with greater fractional triclopyr rates (Fig. 2). Low $R^{2}$ values for $2,4-\mathrm{D}$, aminopyralid, and dicamba indicate that the herbicide rate is a poor predictor for grape yield within the tested rate range. Crop yield was lower overall in 2019 than in 2018, including in nontreated plots, potentially related to a cooler and rainier spring in 2019, but there was no interaction between growing season and herbicide treatment. Therefore, annually repeated drift events do not appear to have caused meaningful multiyear impacts on grape yield, although more specific research, such as on-bud success in the year after exposure and preceding the second drift event, is needed to support this conclusion.

Grape sugar content did not vary with herbicide rate for 2,4-D, aminopyralid, and dicamba, and there were no differences in sugar content among these herbicides. The relationship between triclopyr rate and relative sugar content was significant $(P=$ $0.034)$, and greater sugar content was associated with greater fractional triclopyr rates (Fig. 3). Low $R^{2}$ values for $2,4-\mathrm{D}$, aminopyralid, and dicamba indicate that the herbicide rate is a poor predictor for sugar content within the tested rate range. Sugar content was greater overall in 2019 than in 2018,

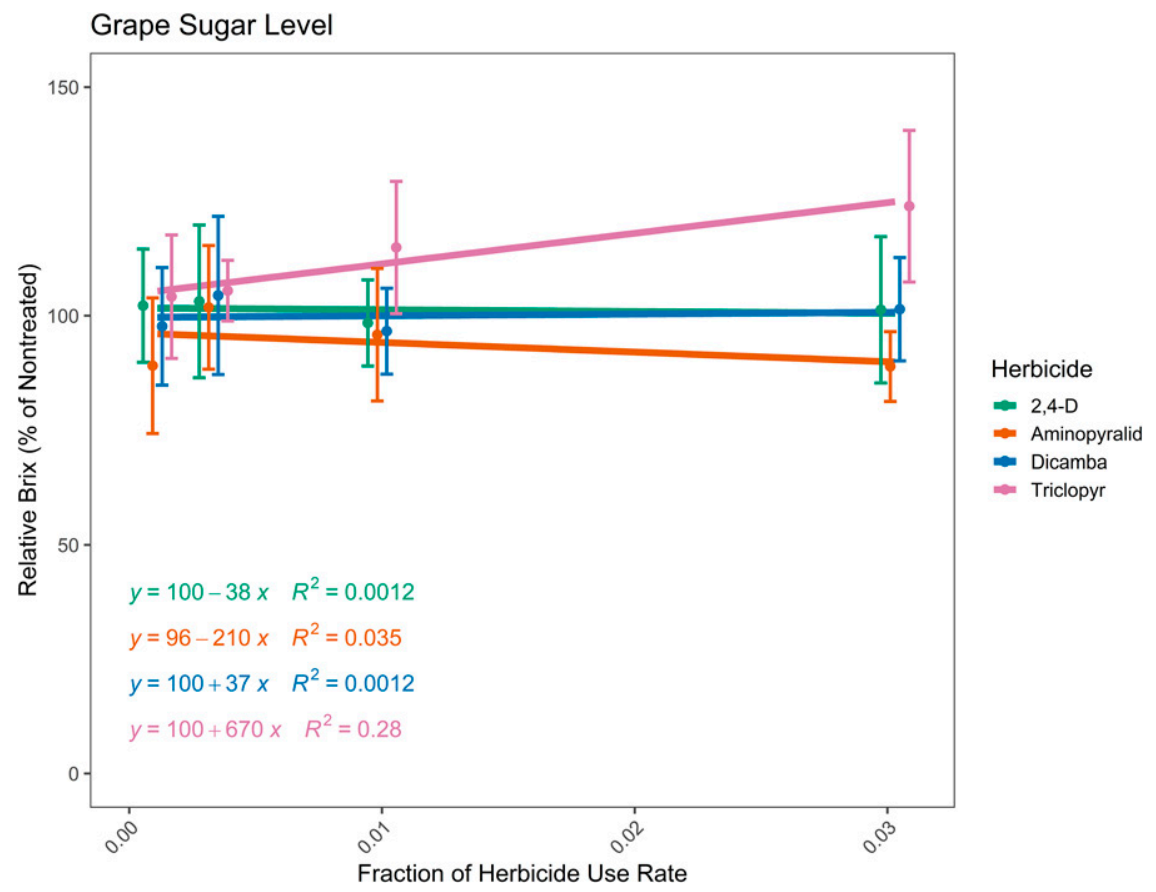

Fig. 3. Grape sugar content across four herbicides applied with four simulated drift rates. Data are pooled across the 2018 and 2019 grape harvests. Linear regression lines depict the relationship between fractional herbicide rate and sugar content relative to the nontreated check, separated by herbicide. Error bars represent SE. Points and error bars at each fractional use rate are slightly offset along the horizontal axis for presentation purposes. dry summer climate of California gives grapes a favorable, uniform environment for recovering from herbicide exposure, and more understanding of the relationships between grape phenology and drift timing could be useful for generalizing the results of our study to areas with temperate climates.

Results from this research suggest that visible herbicide symptoms are not always associated with crop injury, yield reduction, or quality penalties in grape. This study established that the presence of herbicide symptomology is not a good indicator of yield reduction on mature 'Grenache' grapes. These findings demonstrate the difficulty of observing patterns that indicate when management decisions should be made after a suspected offtarget movement event. Furthermore, this study demonstrates the difficulty of distinguishing between auxin herbicides, except for triclopyr, based on grape symptoms. These results highlight the importance of chemical analysis for positive exposure identification. The importance of low-cost and consistent diagnosis is especially acute for grape growers, given the heightened economic risks of establishing specialty and perennial crops.

\section{Literature Cited}

Al-Khatib, K., R. Parker, and E.P. Fuerst. 1992 Foliar absorption and translocation of herbicides from aqueous solution and treated soil. Weed Sci. 40:281-287, https://doi.org/10.1017/ S0043174500057350

Al-Khatib, K., R. Parker, and E.P. Fuerst. 1993. Wine grape (Vitis vinifera L.) response to simulated herbicide drift. Weed Technol. 7:97-102, https://doi.org/10.1017/S0890037X00036940.

Al-Khatib, K. and D. Peterson. 1999. Soybean (Glycine $\max$ ) response to simulated drift from selected sulfonylurea herbicides, dicamba, glyphosate, and glufosinate. Weed Technol. 13:264-270, https://doi.org/10.1017/S0890037X00041713.

Bhatti, M.A., K. Al-Khatib, and R. Parker. 1996. Wine grape (Vitis vinifera) response to repeated exposure of selected sulfonylurea herbicides and 2,4-D. Weed Technol. 10:951-956, https:// doi.org/10.1017/S0890037X00041075.

Bhatti, M.A., K. Al-Khatib, and R. Parker. 1997. Wine grape (Vitis vinifera) response to fall exposure of simulated drift from selected herbicides. Weed Technol. 11:532-536, https://doi. org/10.1017/S0890037X00045371.

Bondada, B.R. 2011. Anomalies in structure, growth characteristics, and nutritional composition as induced by 2,4-dichlorophenoxy acetic acid drift phytotoxicity in grapevine leaves and clusters. J. Amer. Soc. Hort. Sci. 136:165-176, https://doi.org/10.21273/JASHS.136.3.165.

California Department of Food and Agriculture. 2020. California Agricultural Statistics Review, 2018-2019. California Department of Food and Agriculture, Sacramento, CA.

Dintelmann, B.R., M.R. Warmund, M.D. Bish, and K.W. Bradley. 2020. Investigations of the sensitivity of ornamental, fruit, and nut plant species to driftable rates of 2,4-D and dicamba. Weed Technol. 34:331-341, https://doi.org/ 10.1017/wet.2019.118

DiTomaso, J.M. 2000. Invasive weeds in rangelands: Species, impacts, and management. Weed Sci. 48:255-265, https://doi.org/10.1614/ 0043-1745(2000)048[0255:IWIRSI]2.0.CO;2. 
Dixon, S.E., J.L. Henry, D.S. Volenberg, and R.J. Smeda. 2021. Simulated particle and vapor drift of dicamba to 'Vidal blanc' hybrid grapevine under Missouri field conditions. HortTechnology 1:1-10, https://doi.org/10.21273/HORT TECH04854-21.

Kniss, A.R. 2018. Soybean response to dicamba: A meta-analysis. Weed Technol. 32:507-512, https://doi.org/10.1017/wet. 2018.74 .
Kniss, A.R. and J.C. Streibig. 2018. 7 Analysis of covariance (ANCOVA). Statistical analysis of agricultural experiments using R. 18 Oct. 2021. $<$ https://Rstats4ag.org $>$.

Mohseni-Moghadam, M., S. Wolfe, I. Dami, and D. Doohan. 2016. Response of wine grape cultivars to simulated drift rates of 2,4-D, dicamba, and glyphosate, and 2,4-D or dicamba plus glyphosate. Weed Technol. 30:807-814, https://doi.org/10.1614/WT-D-15-00106.1
R Core Team. 2019. R: A language and environment for statistical computing. R Foundation for Statistical Computing, Vienna, Austria.

Suarez, L.A., A. Apan, and J. Werth. 2017. Detection of phenoxy herbicide dosage in cotton crops through the analysis of hyperspectral data. Intl. J. Remote Sens. 38: 6528-6553, https://doi.org/10.1080/01431 161.2017.1362128. 